\title{
CORRENTES POLÍTICAS E PROCESSOS DE INTEGRAÇÃO NA AMÉRICA LATINA: A ALIANÇA DO PACÍFICO EM COMPARAÇÃO AO MERCOSUL E
} À $_{\text {ALBA }}{ }^{1}$

\author{
Bruno Hendler $^{2}$
}

\begin{abstract}
Resumo
O presente artigo tem como objetivo analisar as variáveis condicionantes do surgimento da Aliança do Pacífico (AP), utilizando os conceitos de Bresser-Pereira (Nova Direita, Nova Esquerda e Velha Esquerda) de forma a interpretar os rumos dos projetos de integração na América Latina no pós Guerra Fria. Utiliza-se o método da análise comparada ao levantar dados sobre outros processos de integração regional e colocar a AP em perspectiva conjuntural. A hipótese principal reside no surgimento da AP como um processo de integração regional da América Latina que atrai países com uma série de características em comum, como a não adesão às iniciativas do Brasil (MERCOSUL) e da Venezuela (ALBA), governos com orientação política de direita e de tendência neoliberal, e que apresentam um histórico de proximidade econômica e/ou política com os Estados Unidos. Ao final do trabalho, concluiu-se que, dado o pouco tempo de vida da AP, qualquer previsão de sucesso ou fracasso é arriscada. No entanto, a partir da análise comparada e dos dados levantados, é possível confirmar a hipótese e aferir que a AP é um processo de integração regional que surge como uma alternativa às propostas do MERCOSUL e da ALBA.

Palavras-chave: América Latina; correntes políticas; Nova Esquerda e Nova Direita; Mercosul; Aliança do Pacífico; Alternativa Bolivariana para as Américas.
\end{abstract}

\begin{abstract}
This article aims to analyze the conditioning variables of the emergence of the Pacific Alliance (PA), using Bresser-Pereira's concepts (New Right, New Left and Old Left) to interpret the trends of integration projects in Latin America after the Cold War. We use the method of comparative analysis to collect data on other regional integration processes and put the AP in conjunctural perspective. The main hypothesis lies in the emergence of AP as a process of regional integration in Latin America that attracts countries with a number of common features, such as: non-adherence to the initiatives of Brazil (Mercosul) and Venezuela (ALBA), right wing and the neoliberal governments, and a history of close economic and / or policy ties with the United States. At the end of the work, we assert that given the short AP lifetime, any prediction of success or failure is risky. However, from the comparative analysis and the data collected, it is possible to confirm the hypothesis and to verify that AP is a process of regional integration that serves as an alternative to MERCOSUR and ALBA.
\end{abstract}

Key-words: Latin America, political trends, New Left and New Right; Mercosul, Pacific Alliance, Bolivarian Alternative for the Americas.

\section{Resumen}

Este artículo tiene como objetivo analizar las variables condicionantes de la emergencia de la Alianza del Pacífico (AP), utilizando los conceptos de Bresser-Pereira (la Nueva Derecha, la Nueva Izquierda y la vieja izquierda) para interpretar la dirección de proyectos de integración en América Latina en el post Guerra Fría. Utilizamos el método de análisis comparativo para recopilar datos sobre otros procesos de integración regional y poner la AP en una perspectiva cíclica. La hipótesis principal consiste en la emergencia de la AP como un proceso de integración regional en América Latina que atrae a los países con una serie de características en común, como la falta de adherencia a las iniciativas de Brasil (Mercosur) y de Venezuela (ALBA), gobiernos con orientación política de la derecha y con tendencia neoliberal, y que tienen una historia de proximidad económica y/o política con los Estados Unidos. Al final, se concluyó que, teniendo en cuenta los pocos años de edad de la AP, cualquier

\footnotetext{
${ }^{1}$ DOI deste artigo: 10.5380/recp.v6i2.42025.

2 Mestre em Relações Internacionais pela UnB e doutorando em Economia Política Internacional pela UFRJ. Email: bruno_hendler@hotmail.com.
} 
predicción de éxito o fracaso es deveras arriesgado. Sin embargo, a partir del análisis comparativo y los datos obtenidos, es posible confirmar la hipótesis, es decir, que la AP es un proceso de integración regional alternativo a las propuestas de MERCOSUR y de ALBA.

Palabras Clave: América Latina; corrientes políticas; Nueva Izquierda y Nueva Derecha; Mercosur; Alianza del Pacífico; Alternativa Bolivariana para las Américas.

\section{INTRODUÇÃO}

Passados dois anos da criação da Aliança do Pacífico (AP), muito ainda resta a ser feito no tocante à integração de seus países membros, Chile, Peru, Colômbia e México. Porém, o novo arranjo de convergência política e econômica entre esses países tem sido responsável por atrair a atenção da mídia internacional e de especialistas para uma região frequentemente esquecida do mundo, a América Latina. Encabeçada por países que possuem relações especiais com os Estados Unidos e que têm sido governados por partidos de direita ou da chamada "Nova Esquerda", a iniciativa surge como um contraponto, planejado ou não, ao bloco de países liderados pela "Velha Esquerda" socialista e antiamericana.

A maré de crescimento econômico dos países da AP provoca euforia entre os críticos mais mordazes da politização "à esquerda" do MERCOSUL, que relacionam "o fracasso" do bloco liderado pelo Brasil com "o sucesso da Aliança do Pacífico" (SETTI, 2013). Ora, dois anos é um prazo deveras curto para atribuir sucesso a qualquer iniciativa de integração regional - pode-se dizer, no máximo, que foram dois anos promissores. Tendo isso em mente, a escolha do objeto de análise, a Aliança do Pacífico em meio às vertentes políticas da América Latina, justifica-se pelos impactos econômicos e geopolíticos que tal iniciativa tende a provocar no continente.

Como em um movimento pendular, a alternativa bolivariana ganhou força nos anos 2000 ante o fracasso dos governos neoliberais da década de 1990 em reduzir as desigualdades sociais do continente. Com a morte de Hugo Chávez e o desgaste político de seus seguidores, em especial de Evo Morales na Bolívia e Rafael Correa no Equador, o espectro político da América Latina volta a pender para a liberalização e a integração econômica com os mercados estrangeiros, se não para todos, pelo menos para um grupo considerável de países.

Porém, o contexto do sistema internacional em 2011, quando da concepção da AP, é distinto daquele do Consenso de Washington, que prevaleceu nos anos 90 e levou vários países latino-americanos a crises econômicas decorrentes dos choques de abertura. Três diferenças precisam ser consideradas: a) o desinteresse da política externa norte-americana na região devido a questões "mais urgentes" na economia doméstica e na esfera da segurança no Oriente Médio e na Ásia Central - leia-se, o combate ao terrorismo após o 11 de setembro; b) a ascensão da Ásia Oriental, em especial da China, como polo de atração das exportações 
de commodities e grande responsável pelos altos índices de crescimento econômico do continente; e c) a crise do MERCOSUL e o papel do Brasil na tentativa de fomentar a ideia de "América do Sul” em detrimento de "América Latina” por meio da institucionalização da região, especialmente pela UNASUL.

Para entendermos como esses três fatores afetam o bloco recém-nascido, o artigo de Bresser-Pereira sobre a "Nova Esquerda" nos países do Sul Global é de grande valia. E, uma vez que o economista analisa a governança interna, pretende-se utilizar seu aparato teórico para interpretar a política externa dos países latino-americanos, que compõem o chamado Sul Global.

\section{A NOVA ESQUERDA E A NOVA DIREITA NA AMÉRICA LATINA}

Em decorrência dos fracassos do Consenso de Washington nos anos 90, a década seguinte testemunhou um renascimento de partidos ligados à esquerda latino-americana. Bresser-Pereira caracteriza duas correntes nesse processo: a Velha e a Nova Esquerda:

A Velha Esquerda tem uma visão negativa do nacionalismo, convencida de que o país é cercado por potências imperialistas. Tem, em geral, uma atitude "contra" países avançados, vistos como "potências imperialistas", e prefere antes fechar o país à influência estrangeira a negociar interesses mútuos e conflitantes (BRESSER-PEREIRA, 2000, p. 165).

$\mathrm{Na}$ linha da Velha Esquerda estão os governos de caráter neopopulista, centralizador e antiglobalização, tendo como referência a Venezuela outrora liderada por Hugo Chávez e adeptos como a Bolívia de Evo Morales, o Equador de Rafael Correa, a Argentina dos Kirchner e a Nicarágua de Daniel Ortega - além da proximidade com a "Velhíssima Esquerda" do regime socialista de Fidel Castro em Cuba.

Já a Nova Esquerda defende uma política macroeconômica keynesiana, seus partidos são influenciados por empresários e pela classe média emergente, e a expressão "luta de classes" perde apelo entre seus seguidores. Essa corrente encara a globalização como desafio a ser trabalhado pelo Estado - ao contrário da Velha Esquerda que a vê como ameaça ao sistema corporativista e centralizado. Uma das principais diferenças entre as duas vertentes reside na reforma do Estado:

A Velha Esquerda não está interessada em reformar o Estado. Gostaria de tê-lo grande e burocrático. A Nova Direita compreende a reforma como liberalização e privatização, ou como redução. Para a Nova 
Esquerda, reformar o Estado significa reconstruí-lo, aumentar sua capacidade, recuperar a poupança pública superando sua crise financeira e envolver-se em reforma gerencial. Significa, também, redefinir o papel do Estado, dando às organizações da sociedade civil um papel maior, seja na produção de serviços sociais ou científicos, seja exercendo controle social (BRESSER-PEREIRA, 2000, p. 169).

Ao contrário dos governos populistas, os pensadores da Nova Esquerda não imputam os problemas de seus países a fatores externos (Idem, p. 148), mas defendem a ação gerencial (e não empresarial) do Estado para garantir afluxos de riqueza para o país. Por outro lado, contestam a tese neoliberal de que a globalização esvaziou os interesses nacionais e defendem uma política externa que leve em conta as relações de poder entre os Estados. Por fim, acreditam que o mercado é mais eficiente na alocação de recursos, mas ruim na distribuição de renda, de forma que o Estado deve atuar para reduzir as desigualdades sociais e incentivar os setores de ciência e tecnologia que sirvam aos interesses nacionais.

No Brasil, a Nova Esquerda chegou ao poder com a eleição do presidente Lula, embora muitos traços dessa corrente já estivessem presentes no segundo mandato do presidente Fernando Henrique Cardoso. A tentativa de institucionalizar a América do Sul e defini-la como esfera privilegiada dos interesses e da projeção de influência brasileira reflete a política externa de uma Nova Esquerda pragmática, aberta ao diálogo com polos antagônicos, que possui uma noção razoável do interesse nacional e que, por meio de uma política econômica keynesiana/dirigista, incentiva o comércio intrarregional e a internacionalização das empresas nacionais.

Uma terceira orientação política é analisada por Bresser-Pereira: a Nova Direita. Composta majoritariamente por grupos capitalistas, essa corrente é pró-mercado, próglobalização, e defende uma política econômica neoclássica, a redução do Estado e a liberalização do comércio exterior. Na América Latina, os países membros da AP têm apresentado essas características em variados graus e distintos setores.

A categorização das três correntes traz o risco de generalizações imprecisas quando o assunto é política externa. Embora a Velha Esquerda seja facilmente identificada pela retórica combativa e pela política econômica intervencionista e protecionista, a linha que separa a Nova Esquerda da Nova Direita é tênue e as siglas partidárias tendem a ser enganosas. 


\section{TRÊS VISÕES E UM CONTINENTE}

\subsection{A NOVA ESQUERDA BRASILEIRA E A CONSTRUÇÃO DO ESPAÇO SUL- AMERICANO}

José Luís Fiori (2007, p. 251) afirma que a América Latina é o único lugar do mundo que nunca testemunhou disputas internas por hegemonia regional. Talvez a afirmação seja um tanto exagerada se levarmos em conta a inserção da África e da Oceania no sistemamundo moderno. Porém, o autor está correto ao afirmar que a América Latina, ao longo de seus cinco séculos de história, esteve sujeita a hegemonias, materiais e ideológicas, oriundas do exterior. Primeiro, sob controle das metrópoles ibéricas; no século XIX, a dependência material da Inglaterra e cultural/ideológica da França; e no século XX, a influência, ora branda ora coercitiva, dos Estados Unidos.

Portanto, apesar das divergências e frequentes atritos, deve-se ver com bons olhos o surgimento de correntes genuinamente latino-americanas de inserção internacional nas últimas duas décadas, principalmente após o esgotamento do modelo de substituição de importações proposto pelos intelectuais da CEPAL em meados do século XX.

O primeiro grande polo de inserção internacional e integração regional a surgir na América Latina no pós Guerra Fria decorreu da relação em eixo Brasil-Argentina, gérmen do MERCOSUL. No contexto do regionalismo aberto, a proposta consistia em combinar a abertura ampla da economia, requerida pela globalização, com integração bilateral ou regional, feita de preferências comerciais e visando controlar os efeitos negativos da abertura (CERVO, 2008, p. 79).

Nesse contexto, a iniciativa brasileira fez com que a América do Sul ganhasse maior destaque, em detrimento do conceito de América Latina, tornando a aproximação com a Argentina a força motriz deste processo. O impacto dessa relação bilateral, que passou gradualmente da agenda de segurança para uma série de temas ligados a cooperação econômica, democratização e desenvolvimento, logo foi sentido por toda a região, caracterizando o conceito de "relações em eixo" (CERVO, 2008).

Assim, a parceria Brasil-Argentina, desenhada gradualmente a partir da solução da questão de Itaipu-Corpus, em 1979, e impulsionada de 1985 em diante, com a Ata de Iguaçu, era expressão e resultado de intensa convergência política em torno de objetivos como a consolidação democrática, as estabilidades política e estratégica regional, o resgate da credibilidade externa e a coordenação de posições ante a questão do endividamento externo. Procurar-se-ia materializar a parceria com a promoção de maior nível de interdependência econômica, mediante ações de cooperação em um amplo espectro de setores (VAZ, 2002, p. 77). 
A relação em eixo Brasil-Argentina passou a corresponder à caracterização de Cervo (2008, p. 211) como um diálogo entre parceiros relativamente simétricos, com impactos sobre seus vizinhos e movida por objetivos concretos de ambos os lados. Alguns anos após a implantação da Tarifa Externa Comum (1994), o MERCOSUL passou por uma crise de legitimidade decorrente da desvalorização do Real em 1999 e da subsequente crise econômica na Argentina em 2000. A partir de então, as deficiências do bloco ficaram mais evidentes com a ausência de mecanismos para resolução dos contenciosos comerciais, cada vez mais frequentes, a incapacidade de implementação das regras acordadas e a crise da credibilidade do projeto de integração. Cervo, (2008, p. 512) ainda aponta para o aprofundamento de assimetrias entre os países membros e o retorno do clima de desconfiança entre Brasil e Argentina.

A consolidação da Nova Esquerda no Brasil com o governo Lula teve impactos diretos na postura do país em relação a seus vizinhos. Conforme o MERCOSUL enfrentava dificuldades institucionais e comerciais, a política externa brasileira para seu entorno geográfico mudou de escopo, abordagem e abrangência geográfica. O escopo deixou de ser o regionalismo aberto levado a cabo por governos liberais e a abordagem, por consequência, deixou de ser feita apenas em termos do fortalecimento comercial e passou a lidar com questões de infraestrutura, cooperação tecnológica e projetos de cunho social e ambiental. Por fim, a abrangência geográfica do modelo de integração, que nos anos 90 já deixara de ser hemisférica, dependente dos EUA ou voltada para toda a América Latina, extrapolou o cone sul e passou a vislumbrar a América do Sul como plataforma de atuação.

Do ponto de vista externo, a falta de políticas viáveis dos EUA para o hemisfério, bem como a crise dos governos neoliberais dos anos 90 , gerou um vácuo de poder norteamericano propício à projeção dos interesses brasileiros na América do Sul. Ademais, a consolidação do MERCOSUL incentivou o governo brasileiro a buscar uma plataforma mais abrangente do que o Cone Sul e menos extensa do que a América Latina. Assim, a noção de América do Sul, cogitada desde o governo de Itamar Franco, finalmente saiu do papel e seus principais objetivos extrapolaram o regionalismo aberto dos anos 90, abordando questões de integração, segurança regional, estabilidade democrática, desenvolvimento de infraestrutura e comércio (VILLA In SARAIVA, 2010, p. 157; COUTO, 2009, p. 49). Segundo Fernando Henrique Cardoso (2001, p. 10):

(...) o êxito do Mercosul foi o que tornou possível para nós contemplar um processo mais amplo de integração sul-americana, baseado na convergência dos dois blocos comerciais sub-regionais, assim como no desenvolvimento de uma infraestrutura física de integração nas áreas de transporte, energia e comunicações. 
A relação Brasil-Argentina tornou-se "estratégica" enquanto vetor de estabilização da América do Sul, sendo impossível dissociá-la dos mecanismos de integração regional. No entanto, o MERCOSUL tornou-se um projeto difícil de ser gerenciado e deixou de ser prioridade para a diplomacia brasileira, a qual passou a buscar um processo mais amplo de integração regional (LESSA, 2010, p. 122).

Assim, o Itamaraty deu prosseguimento à formação do espaço sul-americano, enfatizando o princípio da cordialidade oficial com os vizinhos e o fomento de uma identidade comum (ainda que contestada), pautada pela solidariedade entre governos de diferentes orientações políticas, mas em sua grande maioria, de esquerda e centro-esquerda. Em 2000 foi realizada a primeira reunião de presidentes da América do Sul, em Brasília, pavimentando o caminho para a Comunidade Sul-Americana de Nações (CASA), criada em 2004, e que em 2008 se transformaria na União das Nações Sul-Americanas (UNASUL).

Ao longo dessa evolução institucional houve muito debate quanto ao escopo e aos principais objetivos da organização, culminando numa série de declarações de princípios nobres mas pouco práticos, como a paz, o desenvolvimento sustentável e o multilateralismo. A partir dessas declarações oficiais, de projetos implementados e das relações ora cooperativas ora conflituosas entre os países membros, se sobressaíram as questões ligadas à integração física, à segurança regional e ao desenvolvimento.

O principal fruto da vontade política de integração na década de 2000 foi o plano de ação para a Integração da Infraestrutura Regional da América do Sul (IIRSA). Seus principais objetivos, explicitados no ato de sua criação, são: identificação de obras de interesse bilateral e sub-regional; identificação de fórmulas inovadoras de apoio financeiro para os projetos de infraestrutura, e; adoção de regimes normativos e administrativos que facilitem a interconexão e a operação dos sistemas de energia, de transportes e de comunicações ${ }^{3}$.

Passados dez anos de sua criação, os resultados da IIRSA são consideráveis embora ainda apresentem lacunas. Couto (2009, p. 68) critica o processo decisório de caráter técnico e a ausência de visão estratégica de longo prazo que não respondem o seguinte questionamento: deve-se buscar uma integração física que favoreça o desenvolvimento conjunto de partes isoladas do continente ou uma que favoreça a manutenção do tradicional modelo agroexportador? Há ainda o problema da intensificação da assimetria entre a econômica brasileira, que responde por mais da metade do PIB da América do Sul, e o uso

\footnotetext{
${ }^{3}$ Comunicado de Brasília. Disponível em http://www.iirsa.org/BancoMedios/Archivos/comunicado_de_brasilia.doc. Acesso em: 25/09/2013.
} 
do BNDES para financiar projetos de interesse brasileiro, como na questão energética com a Bolívia e com a Venezuela. Por esse caminho, o crescimento econômico da América do Sul implicaria na construção de uma região periférica e tributária à economia brasileira, e a ilusão do desenvolvimento seria reproduzida em escala regional.

No tocante à segurança regional, a institucionalização da América do Sul propicia maior margem de manobra para a diplomacia de tradição conciliadora do Brasil. Desde o processo de redemocratização nos anos 80, a Bacia do Prata deixou de ser a principal fonte de insegurança ao passo que as ameaças da Bacia Amazônica ganharam relevância, em especial o narcotráfico, movimentos guerrilheiros e a imigração ilegal. Ainda é preciso destacar o papel de mediador exercido pelo Brasil nos atritos entre os países da região, como o incidente envolvendo Equador, Colômbia e o acampamento das Forças Armadas Revolucionárias da Colômbia (as FARC) naquele país.

A criação do Conselho de Defesa Sul-Americano (CDS) em 2008 derivou da iniciativa brasileira em garantir a estabilidade regional e afastar a influência dos EUA na América do Sul. Dessa forma, busca-se coordenação e cooperação em segurança e política de defesa entre os Estados sul-americanos que possa construir a confiança mútua e impedir situações de conflito como o episódio Colômbia-Equador-FARC, de 2008 (KANG-DEOK, 2011, p. 69), canalizar esforços para lidar com o tráfico de drogas e o crime organizado, e prevenir a ingerência norte-americana na região.

\subsection{A VELHA ESQUERDA LATINO-AMERICANA E A ALTERNATIVA BOLIVARIANA PARA AS AMÉRICAS (ALBA)}

A eleição de Hugo Chávez para presidente da Venezuela em 1999 deu origem à segunda corrente latino-americana de inserção internacional e integração regional: a Alternativa Bolivariana para as Américas (ALBA). No âmbito interno, Chávez implantou o chamado "socialismo do século XXI", que incorpora os traços clássicos da Velha Esquerda caracterizada por Bresser-Pereira: a ampliação do aparato estatal com a admissão de burocratas ligados ao partido governista; a intervenção direta do Estado na economia, inclusive com a nacionalização de empresas de setores considerados estratégicos; o Estado como responsável pelo fornecimento de serviços e programas sociais; e a adoção de um discurso paternalista e neopopulista focado na luta de classes e amparado pelo carisma do presidente. 
Ao sair ileso da tentativa de golpe militar apoiada por elites capitalistas e pela CIA em 2002, Hugo Chávez elevou o tom do discurso antiamericano e antiglobalização. No plano externo, buscou a aproximação com outros países também chefiados por líderes da Velha Esquerda e em 2004 encabeçou, juntamente com Cuba, a criação da Alternativa Bolivariana para as Américas. Como consequência do fracasso do Consenso de Washington em reduzir as desigualdades sociais na América Latina e em resposta a proposta norte-americana da ALCA, os chefes de Estados de Bolívia, Equador, Nicarágua e Argentina aderiram, em graus variados, às práticas da Velha Esquerda e se aproximaram da proposta bolivariana de Hugo Chávez.

Dos países citados, apenas a Argentina de Nestor e Cristina Kirchner não aderiu oficialmente à ALBA, embora existam fortes indícios de que as campanhas presidenciais do casal tenham sido patrocinadas por dinheiro venezuelano. Os demais, Equador, Bolívia, Nicarágua, Suriname e alguns pequenos países do Caribe foram, um a um, aderindo à proposta bolivariana que, em 2009 teve seu nome alterado de "Alternativa" para "Aliança Bolivariana das Américas".

Com um discurso de combate às mazelas da globalização e aos desmandos dos EUA na América Latina, Chávez se utilizou da renda gerada pela exportação de petróleo, quando - nos anos 2000 - a média do preço do barril saltou de 30 para cerca de 100 dólares, para fazer da Venezuela um novo polo de atração política e econômica na região.

A principal ferramenta de integração da ALBA deriva dos conceitos de projetos e empresas "Grannacionales". Enquanto no modelo da Nova Esquerda brasileira o Estado adquire funções dirigistas e busca amparar a internacionalização da iniciativa privada, no modelo da Velha Esquerda venezuelana o Estado assume o papel de empresário e opera de acordo com objetivos políticos voltados para os setores de desenvolvimento social e de distribuição de renda indo, muitas vezes, "contra os conceitos clássicos de economia" (BACKER, 2010, p. 233).

De acordo com o documento oficial do VI Encontro da ALBA, toda "empresa grannacional” (EG) está inserida em um "projeto grannacional” (PG) que, por sua vez, é definido como "um programa de ação dirigido a cumprir os princípios e objetivos da ALBA, que tenha sido validado pelos países membros do bloco e cuja execução envolva dois ou 
mais países". Em outras palavras, os PGs estabelecem estratégias de ação em setores específicos e as EGs os colocam em prática ${ }^{4}$.

De acordo com fontes oficiais ${ }^{5}$, os projetos e empresas grannacionais estão em diferentes fases de maturação e operam em diferentes setores, como o banco da ALBA; o programa de alfabetização; o intercâmbio de programas humanitários de saúde e alimentos, como o ALBA-Foods, o "Missión Barrio Adentro" e o "Operación Milagro" de habitação; o setor de energia com as EGs Petrocaribe, Petrosur e Petroandina; além de outras EGs nos setores de indústria pesada, comércio, meio-ambiente e turismo.

Por serem empresas públicas, as EGs dispõem de uma série de subsídios que visam melhorar a qualidade de vida das camadas mais pobres da sociedade. Nesse sentido, o conceito de "preço justo" (entenda-se subsidiado) facilita o acesso a alimentos, energia e serviços básicos, mas traz consigo a ideia de que o Estado pode controlar a oferta e a demanda de produtos em nome da solidariedade - gerando perigosas distorções de mercado.

Grosso modo, os projetos são financiados pela Venezuela que, através das EGs, tende a vincular os demais países à sua economia. Um exemplo de cooperação que passou para o escopo da ALBA é a "Missión Barrio Adentro", fruto da relação especial entre Venezuela e Cuba. Em troca do petróleo venezuelano, Cuba passou a enviar médicos e outros profissionais da saúde para atuar no país sul-americano e treinar seus colegas de ofício. Outros projetos de EGs incluem o setor cafeeiro entre Venezuela e Dominica, mineração entre Venezuela e Equador, energia entre Venezuela e Bolívia, e muitos outros (BACKER, 2010, p. 236).

Um dos projetos mais ambiciosos do bloco é a criação de um sistema monetário comum para reduzir a dependência do dólar, responder à crise econômica internacional de 2008/2009 e intensificar o comércio intrabloco. Com esses objetivos e tendo como base teórica alguns princípios keynesianos sobre integração monetária, o SUCRE (Sistema Único de Compensação Regional de Pagamentos) foi criado em 2009. Ainda que as economias nacionais da ALBA sejam pouco complementares, não sejam territorialmente contíguas e careçam de uma boa infraestrutura nos transportes e comunicações, o uso do SUCRE pelos bancos centrais tem ganhado importância e as trocas comerciais intrabloco cresceram consideravelmente nos últimos anos.

\footnotetext{
4 Conceptualización de proyecto y empresa grannacional em el marco del ALBA. Disponível em http://www.alba-tcp.org/contenido/conceptualizacion-de-los-grannacional__Acesso em: 25/05/2013.

5 Empresas Grannacionales. Disponível em: http://www.embajadacuba.com.ve/alba/empresasgrannacionales/._Acesso em: 25/05/2013.
} 
Boa parte das EGs ainda não saiu do papel e seus impactos permanecem na esfera do discurso de uma América Latina mais igualitária e solidária. Assim, o grande desafio do conceito "grannacional" consiste em colocar em prática um modelo de integração regional planejado e controlado por governos que possuem uma orientação ideológica da Velha Esquerda. Se na esfera interna esses governos já são obrigados a lidar com uma série de problemas de regulação do mercado, na esfera internacional esses desafios multiplicam-se diante da necessidade de se fazer convergir o desenvolvimento e a integração regional com os interesses particulares de cada país.

A relação entre a Nova e a Velha Esquerda na última década tem sido marcada por episódios de convergências e divergências. A principal convergência veio com a adesão da Venezuela ao MERCOSUL. Apesar da crise institucional gerada no âmbito da instituição, em decorrência da suspensão do Paraguai, o pretexto tornou-se a oportunidade para coroar a aproximação entre a Nova Esquerda brasileira e a Velha Esquerda venezuelana. Com a morte de Hugo Chávez, os rumos dessa relação são incertos e o mais provável é que a Venezuela seja integrada no processo de expansão regional do Brasil.

\subsection{A ALIANÇA DO PACÍFICO E A ALTERNATIVA DO LIVRE MERCADO}

O contexto do surgimento da Aliança do Pacífico é muito diferente dos anos 90, que viram a criação do MERCOSUL, e dos anos 2000, que viram o fortalecimento da Velha Esquerda e a criação da ALBA. Tanto a onda neoliberal do regionalismo aberto quanto a relutância ferrenha à ideia da ALCA arrefeceram em partes da América Latina e a nova conjuntura econômica mundial favorece a articulação de países que, em sua maioria, têm sido governados por líderes com traços da Nova Direita.

A Aliança do Pacífico, formada por Chile, Peru, Colômbia e México surge em um contexto de ascensão econômica da Ásia, recuperação econômica dos EUA pós crise de 2008/2009 e crise institucional (alguns diriam existencial) do bloco liderado pela Nova Esquerda brasileira, o MERCOSUL. Apesar do pouco tempo de existência, a AP aparece como uma iniciativa ousada que requer uma análise a partir de quatro eixos: a orientação dos líderes e partidos políticos que têm governado os países membros nos últimos anos; a diplomacia e o grau de interação econômica entre eles; e dois eixos que analisam a relação da AP com os EUA e com a China. 
Se a Venezuela é o motor da ALBA (75\% do PIB do bloco) e o Brasil o motor do MERCOSUL (80\% do PIB) respectivamente, a AP não tende a gravitar em torno de uma única economia, ainda que o México seja responsável por 60\% do PIB do bloco. Isso decorre não apenas da menor assimetria econômica entre os membros, mas principalmente devido ao escopo liberal da integração e à não contiguidade territorial entre os países. Os gráficos abaixo $^{6}$ mostram a parcela do PIB de cada um dos países membros nos três blocos econômicos em questão.

No primeiro gráfico, deve-se ter em mente que o cálculo começa anos antes da criação da AP, o que não invalida nossa análise. Nele, é notória a redução relativa da parcela mexicana frente ao crescimento da Colômbia e do Chile. Ainda, cabe ressaltar que há um maior equilíbrio entre os membros deste bloco, ou seja, o menor PIB da AP (Peru) responde por cerca de 10\% do total, enquanto os menores PIBs do MERCOSUL (Paraguai) e da ALBA (Dominica) não passam de cerca de $1 \%$ do total.

Gráfico 1 - Aliança do Pacífico: Parcela do PIB dos países membros

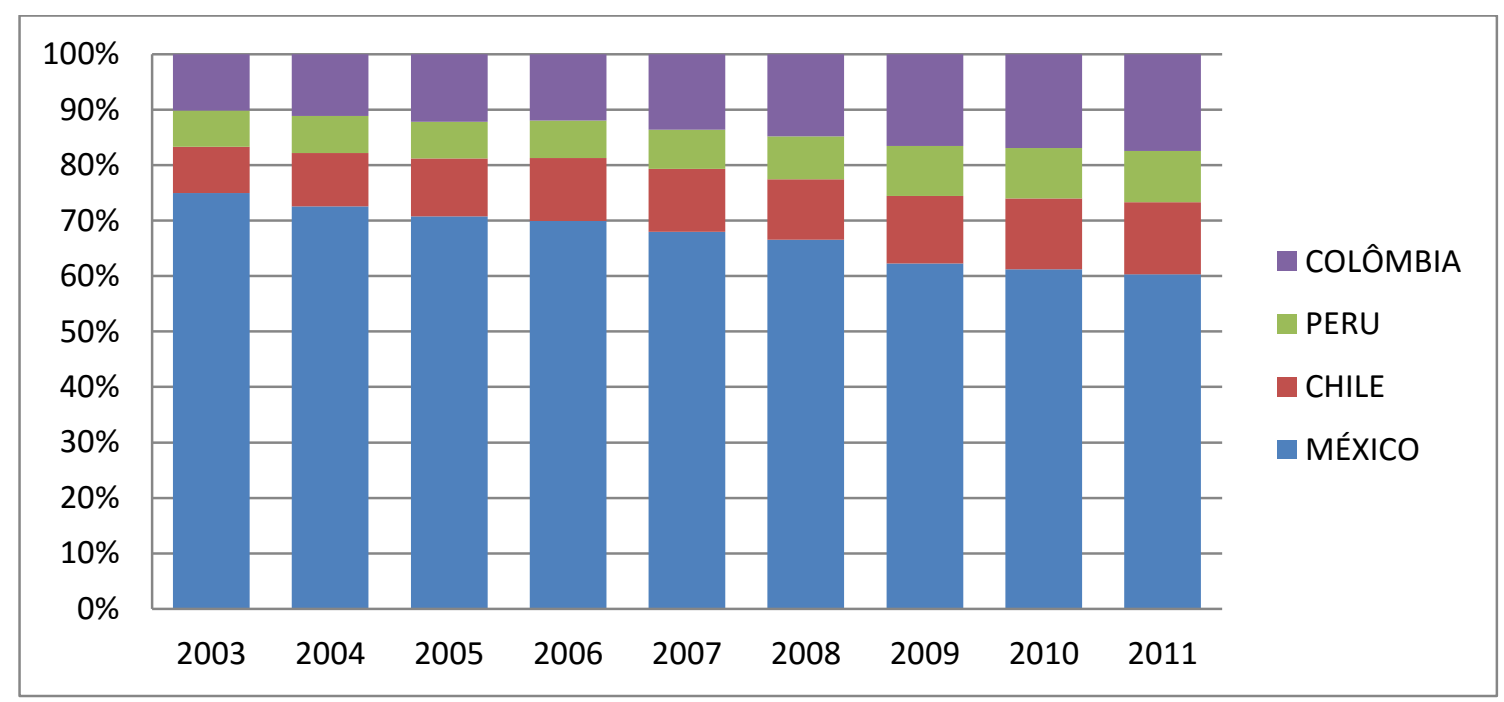

Fonte: http://data.worldbank.org.

\footnotetext{
${ }^{6}$ Dados disponíveis em: http://data.worldbank.org/.
} 
Gráfico 2 - Mercosul: Parcela do PIB dos países membros

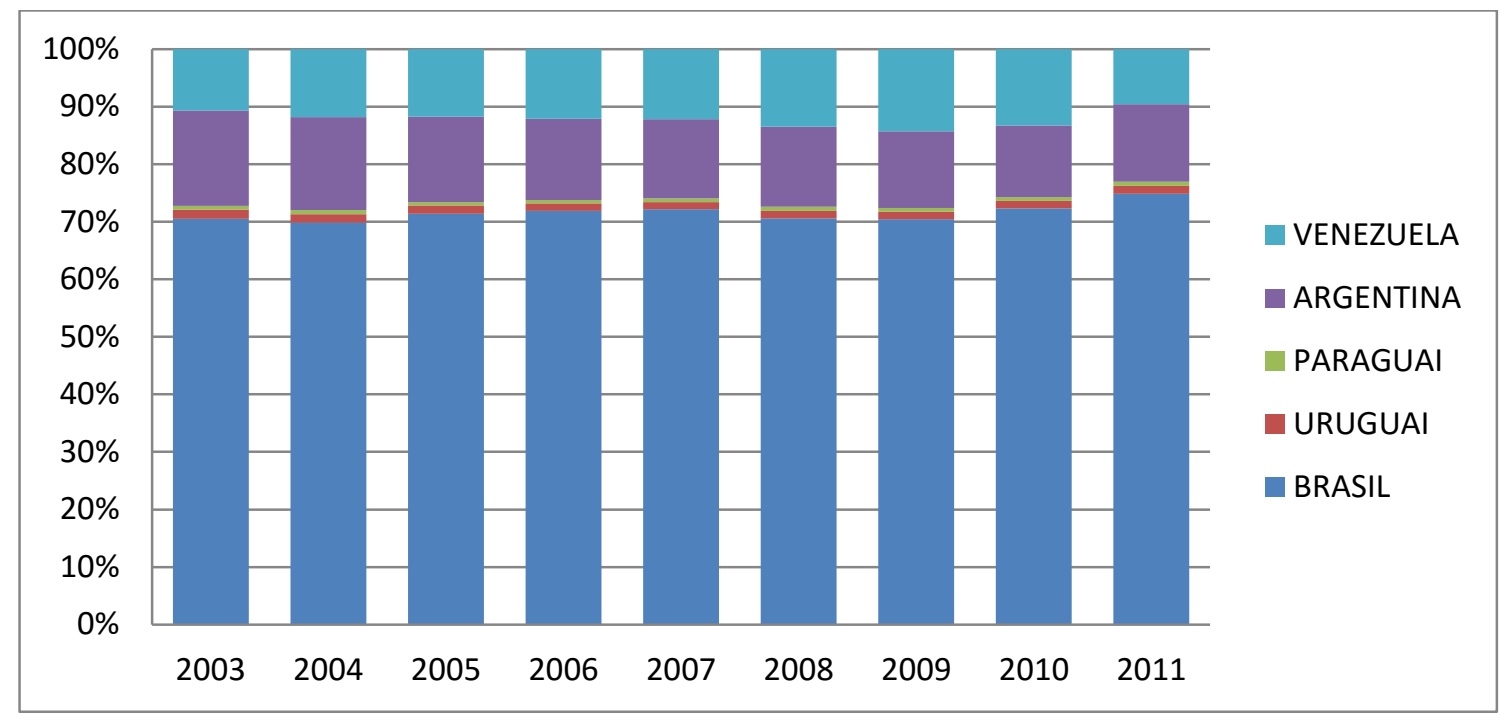

Fonte: http://data.worldbank.org.

Gráfico 3 - ALBA: Parcela do PIB dos países membros

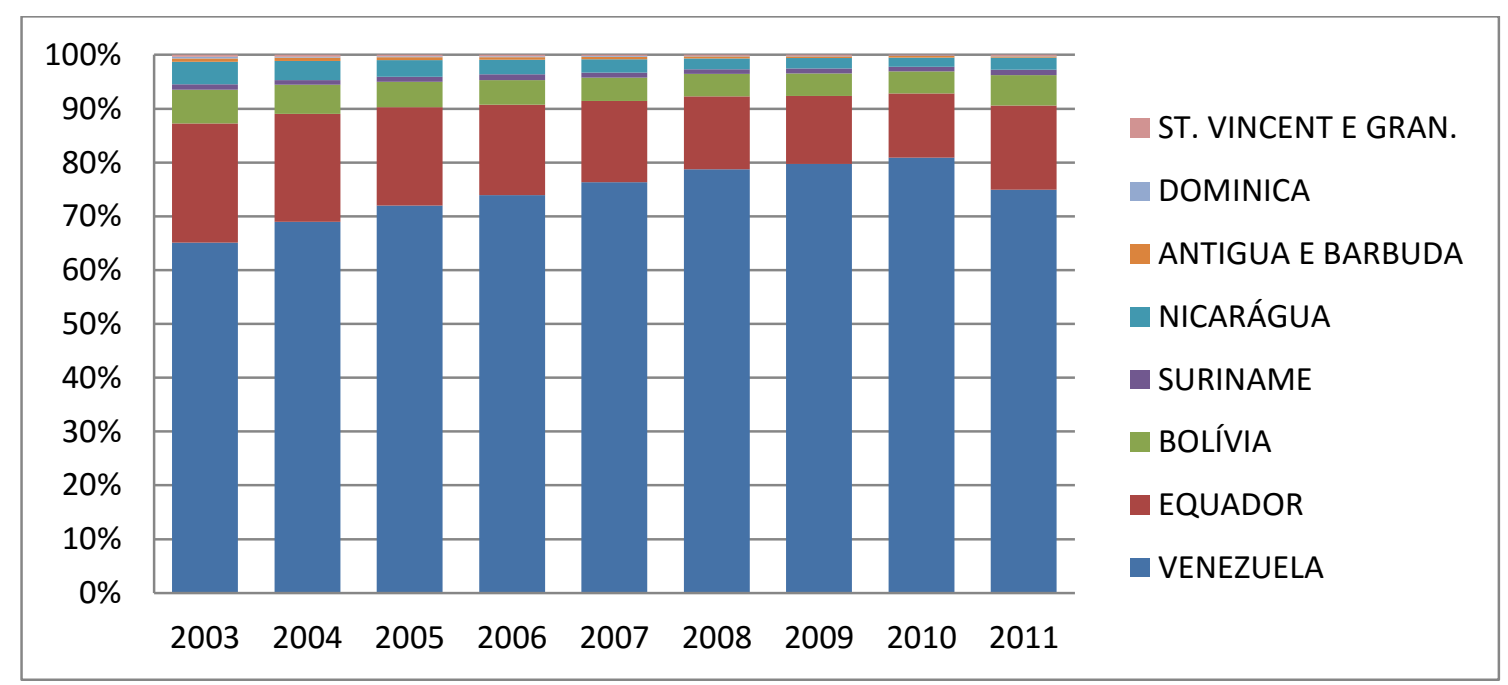

Fonte: http://data.worldbank.org.

Independente das siglas partidárias, os quatro países da AP têm sido administrados por governos que podem ser caracterizados como a Nova Direita, principalmente em termos de política econômica.

Da saída do General Pinochet, em 1990, até 2010, o Chile foi governado por uma coalizão de partidos de esquerda e centro-esquerda que, apesar de promover reformas políticas e sociais, manteve o modelo de livre mercado e o desenvolvimento voltado para as exportações, consolidados durante a ditadura militar. A eleição de Sebastián Piñera em 2010 
trouxe ao poder um partido de direita que manteve a política econômica implantada por Pinochet e continuada pela concertação socialista. Portanto, os vinte anos de liderança da esquerda não invalidam a afirmação de que o Chile, por pelo menos quatro décadas, teve uma inserção econômica internacional com características da Nova Direita. O retorno de Michelle Bachelet à presidência, após o governo de Piñera, dá sinais de que algumas diretrizes de política econômica sofram uma leve guinada na direção do intervencionismo estatal.

Peru, Colômbia e México não fogem à regra. Quaisquer que tenham sido as siglas partidárias que governaram esses países na última década, as diretrizes de política econômica mantiveram alguns traços essenciais do neoliberalismo, caracterizando assim os governos da Nova Direita.

Conforme Felipe Bulnes, Embaixador do Chile nos EUA, e Harold W. Forsyth, Embaixador do Peru nos $\mathrm{EUA}^{7}$, a proximidade entre os quatro países decorre mais de afinidades políticas e princípios compartilhados do que da integração econômica propriamente dita. Dado o pouco tempo de existência do bloco, é natural que o estreitamento de laços comerciais, financeiros e de circulação de pessoas não esteja consolidado. Enquanto o comércio intrabloco do MERCOSUL já chegou a 25\% (em 1998) e hoje está em torno de $15 \%{ }^{8}$, o comércio entre os membros da AP é ainda muito baixo. Porém, uma série de iniciativas ambiciosas pretende reduzir as distâncias que os separam. As principais são?:

- Liberalização do comércio intrabloco. Em janeiro de 2013 os países membro concordaram em eliminar barreiras tarifárias para 90\% das mercadorias que circulam dentro da AP.

- Circulação de pessoas. Com vistas a promover o turismo, a circulação de empresários e o intercâmbio de estudantes, planeja-se eliminar a necessidade de vistos para estadia de até 180 dias entre os quatro países, além da criação de 100 bolsas de estudo anuais para as universidades dos países membros.

- Integração de mercados financeiros. Desde maio de 2011 os três membros sul americanos (Chile, Peru e Colômbia) combinaram seus mercados financeiros em uma bolsa de valores, o Mercado Integrado Latino-Americano (MILA), visando facilitar e incrementar os investimentos estrangeiros. Ainda que o MILA tenha surgido fora do âmbito da AP, a possibilidade de adesão do México tem sido influenciada diretamente pela criação do bloco.

\footnotetext{
Áudio da $7^{\mathrm{a}}$ reunião de cúpula presidencial da Aliança do Pacífico, disponível em http://csis.org/multimedia/audio-pacific-alliance, acesso em 31/05/13.

${ }^{8}$ Dados disponíveis em UNCTADstat.

${ }^{9}$ What is the Pacific Alliance? Disponível em: http://www.as-coa.org/articles/explainer-what-pacific-alliance, acesso em 28/05/2013.
} 
Outro traço comum desses governos é a relação especial com os EUA, seja em termos de comércio ou de segurança. Segundo Petras (2009) a política externa dos EUA para a América Latina apresenta três grandes objetivos que foram mantidos na transição BushObama: a) garantir o apoio de governos de direita (ou da Nova Direita, no nosso estudo); aumentar a influência sobre governos "centristas" (ou da Nova Esquerda); e c) isolar e enfraquecer governos populistas de esquerda (ou da Velha Esquerda).

Apesar das diferenças no discurso, a continuidade de Bush para Obama na postura em relação à América Latina é nítida nos seguintes termos (PETRAS, 2009):

- Baixa prioridade da América Latina na política externa dos EUA. A região é colocada em quinto lugar na agenda da Casa Branca, após a recessão (e recuperação) da economia doméstica, a Guerra ao Terror no Oriente Médio e Ásia Central, a formulação de política econômica em conjunto com a União Europeia e a formulação de estratégias econômicas e militares com Rússia e China;

- Ênfase na esfera da segurança e combate ao narcotráfico em detrimento de programas de longo prazo voltados para a redução da pobreza e o desenvolvimento econômico;

- Postura ambígua de defender o livre mercado e praticar o protecionismo especialmente com países mais competitivos como o Brasil;

- Tentativa de separar os governos da Nova e da Velha Esquerda;

- Apoio a movimentos separatistas como forma de desestabilizar os governos da Velha Esquerda (Santa Cruz na Bolívia; Guayaquil no Equador; e Maracaibo na Venezuela). Assim, os quatro países membros da AP já haviam celebrado acordos de livre comércio com os EUA antes mesmo da criação do bloco. Os impactos desses acordos são variados mas, em geral, facilitam a entrada de investimentos norte-americanos e estreitam as relações comerciais com os EUA.

$\mathrm{Na}$ esfera da segurança, México e Colômbia são aliados tradicionais dos norteamericanos no combate ao narcotráfico e, ao longo das últimas duas décadas, passaram a receber treinamento, assessoria, material e bases militares dos EUA. O "Plano Colômbia", por exemplo, originalmente pensado em 1999 como um projeto de desenvolvimento econômico e construção da paz adquiriu, com o financiamento dos norte-americanos, um viés militarista e policial, deixando de lado o caráter econômico-social e dando margem a denúncias de desrespeito aos direitos humanos por parte de grupos paramilitares como as Autodefensas Unidas de Colombia (AUC) (RIPPEL, 2004, p. 3-4). De forma similar, o fluxo 
migratório de mexicanos para os EUA passou a ser tratado como questão de segurança, sem levar em conta que muitos emigrantes e traficantes optam por esses caminhos em decorrência da falência e da perda de competitividade da agropecuária mexicana após a adesão do país, sem fundos compensatórios, ao NAFTA (PETRAS, 2009).

Se as relações bilaterais com os EUA são fortes, o mesmo ainda não se pode dizer da relação do bloco com este país. Embora a AP se encaixe na estratégia norte-americana de se aproximar de governos da Nova Direita na região, a última reunião de cúpula do grupo, em maio de 2013 na cidade de Cali, teve a ausência de representantes dos EUA na condição de observadores - status ocupado por Espanha, Austrália, Japão, Canadá, Nova Zelândia e Uruguai, além de Estados postulantes a adesão como Costa Rica, Panamá e Guatemala. Assim, embora o governo dos EUA não manifeste publicamente grande entusiasmo pela iniciativa, o estreitamento de laços com a AP a partir das fortes relações bilaterais com seus membros é quase inevitável.

Por fim, se a AP fortalece o grupo de países que têm relações próximas com os EUA e isola a Velha Esquerda, a ascensão da China torna-se um desafio para os norte-americanos pois, assim como em outras partes do mundo, os arranjos de poder construídos por eles ao longo dos anos têm sido desestabilizados pela atração da economia e da diplomacia chinesas. A América Latina continua (e continuará) sendo uma região de nítida predominância militar dos EUA, mas assim como na Ásia Oriental, no Oriente Médio e na África, o papel desempenhado pela China, tanto em termos econômicos quanto em termos de capital político, tende a crescer. Em outras palavras, a AP pode ser útil aos EUA como contraponto à ALBA e ao MERCOSUL, mas também pode tornar-se o canal de aproximação da China com a América Latina - e a localização geográfica dos membros da AP, bem como as declarações oficiais de seus líderes, favorecem esse processo.

A aproximação com a Ásia, e mais especificamente com a China, está no discurso e nos números da AP. Para o Embaixador da Colômbia nos EUA, Carlos Urrutia, o bloco não é apenas um "acordo de livre comércio", mas um processo dinâmico que busca profunda integração regional e inserção internacional, especialmente com a Ásia-Pacífico ${ }^{10}$. Embora ainda não haja uma aproximação coordenada do bloco com esta região, seus membros já possuem acordos bilaterais de comércio com países asiáticos: Chile e Peru com a China e a Coreia do Sul; Chile e México com o Japão; e a Colômbia assinou recentemente um acordo com a Coreia do Sul e está em negociações com o Japão (KOTSCHWAR et. al, 2013).

10 Áudio da $7^{\mathrm{a}}$ reunião de cúpula presidencial da Aliança do Pacífico, disponível em http://csis.org/multimedia/audio-pacific-alliance, acesso em 31/05/13. 
Ademais, de 2000 a 2011, as exportações dos países da AP para os EUA caíram em termos relativos, de $77 \%$ para $58 \%$, enquanto que China e ASEAN passaram de $1 \%$ a $7 \%$.

Portanto, ao enfatizar o escopo econômico da AP, seus líderes deixam claro que pretendem manter a relação de proximidade política com os EUA e de indiferença, ou mesmo rejeição, às alternativas do MERCOSUL e da ALBA. Porém, reconhecendo a gradual transição da riqueza mundial dos EUA para a Ásia, Chile, Peru, Colômbia e México demonstram que não pretendem perder o bonde da história e se preparam para encurtar as distâncias entre os dois lados do Oceano Pacífico.

\section{CONSIDERAÇÕES FINAIS}

A criação do MERCOSUL foi cercada de muita euforia e otimismo no começo dos anos 90 e a construção da ALBA nos anos 2000, apesar de polêmica, também gerou grandes expectativas entre seus membros. As altas taxas de crescimento foram responsáveis por esta euforia - no primeiro caso, devido ao imenso fluxo de investimentos estrangeiros que deram corpo ao "regionalismo aberto"; e no segundo devido aos superávits comerciais decorrentes da exportação do petróleo venezuelano.

Porém, as ondas de crescimento econômico são passageiras, não duram para sempre - e os latino-americanos o sabem muito bem. Os meios de comunicação exaltam que os membros da AP têm apresentado um crescimento superior à média do continente e utilizam este fato como justificativa para prever a prosperidade futura do bloco. Mas seus líderes sabem que é preciso muito mais do que um PIB de 4\% para lograr sucesso na iniciativa.

A criação da AP contrapõe-se ao antiamericanismo difundido pela Velha Esquerda latino-americana e enfraquece a iniciativa brasileira de construção de uma "América do Sul" integrada e mais autônoma frente aos norte-americanos. Por outro lado, a aproximação do bloco com os EUA não é fato consumado e a ênfase dos líderes no outro lado do Pacífico dá a impressão de que a AP buscará equilibrar-se entre as perspectivas do comércio com a Ásia e os benefícios das relações bilaterais (e em bloco) com os EUA, seja em termos de acesso privilegiado ao mercado norte-americano ou da cooperação política e militar com este país.

Portanto, esteja a AP voltada para a Ásia ou para os EUA, sua grande contribuição inicial é a convergência de países mais abertos ao livre comércio e menos alinhados ao discurso antiamericano da Velha Esquerda. Por fim, o novo bloco abre uma encruzilhada sobre que papel o Brasil pretende desempenhar na América do Sul: o da aproximação com a 
ALBA e da politização do MERCOSUL através da UNASUL, ou o da aproximação com o continente asiático e da liberalização gradual de sua economia.

\section{REFERÊNCIAS}

BACKER, Larry C. 2010. Globalization and the socialista multinational: Cuba and ALBA's Grannacional projects at the intersection of business and human rights. Cuba in transition. ASCE, 2010.

BRESSER-PEREIRA, Luiz C. 2000. A nova Esquerda: uma visão a partir do sul. Revista Filosofia Politica, nova série, vol. 6, p. 144-178.

CARDOSO, Fernando H. 2001. A Política Externa Brasileira no início de um novo século. Brasília: RBPI, vol. 44.

CERVO, Luiz A. 2008. Inserção internacional: formação dos conceitos brasileiros. São Paulo: Saraiva.

COUTO, Leandro, F. 2009. O horizonte regional do Brasil: integração e construção da América do Sul. Curitiba: Juruá.

FIORI, José L. 2007. O poder global e a nova geopolítica das nações. São Paulo: Boitempo.

KANG-DEON, Jeong. 2011. As políticas externa e de defesa do Brasil para a estabilidade regional na América do Sul desde o fim da Guerra Fria. Brasília: Dissertação de Mestrado Instituto de Relações Internacionais da Universidade de Brasilia (IREL-UnB).

KOTSCHAWAR, Barbara; SCHOTT, Jeffrey J. 2013. The next big thing? The Trans-Pacific Partnership \& Latin America. Americas Quarterly.

LESSA, Antônio C. 2010. Brazil's strategic partnerships: na assessment of the Lula era (20032010). RBPI, vol. 53.

PETRAS, James. US-Latin America relations in a time of rising militarism, protectionism and pillage. Global Research, 2009. Disponível em: http://www.globalresearch.ca/us-latinamerican-relations-in-a-time-of-rising-militarism-protectionism-and-pillage/13601 Acesso: 25/05/2013.

RIPPEL, Márcio P. 2004. O Plano Colômbia como instrumento da política norte-americana para a América Latina e suas consequências. Escola de Guerra Naval.

SARAIVA, Miriam G. 2010. Brazilian foreign policy towards South america during the Lula Administration: caught between South America and Mercosur. Brasília: RBPI, vol. 53.

SETTI, Ricardo. México, Colômbia, Peru e Chile mostram ao Brasil o que deveria ser feito em vez de permanecer atolado no Mercosul. Revista Veja, 02/06/2013. Disponível em: http://veja.abril.com.br/blog/ricardo-setti/vasto-mundo/mexico-colombia-peru-e-chile- 
HENDLER, Bruno. Correntes políticas e processos de integração na América Latina: a aliança do pacífico em comparação ao MERCOSUL e à ALBA.

mostram-ao-brasil-o-que-deveria-ser-feito-em-vez-de-permanecer-atolado-no-mercosul/ Acesso: 05/06/2013.

VAZ, Alcides C. 2002. Cooperação, integração e processo negociador: a construção do Mercosul. Brasília: IBRI. 